\title{
Computer Enumeration of Significant Implicational Universals of Kinship Terminology
}

\author{
Raúl E. Valdés-Pérez \\ Computer Science Department \\ Carnegie Mellon University \\ Pittsburgh, PA 15213 - USA \\ Vladimir Pericliev \\ Department of Mathematical Linguistics \\ Institute of Mathematics and Informatics, bl. 8 \\ Bulgarian Academy of Sciences, 1113 Sofia - Bulgaria
}

\begin{abstract}
The discovery of general patterns and their subsequent explanation is a familiar method in linguistics and other cross-cultural research. This paper addresses the computerized enumeration of significant cultural and linguistic patterns, specifically implicational universals. We dispute published suggestions that the mechanical generation of universals is inadvisable, by arguing that such claims do not distinguish clearly the noticing of a pattern with its explanation. We make use of a simple, principled method that uses permutation tests to estimate whether the discovered universals are significant. Finally, these methods are used to mine the rich kinship dataset contributed by G. P. Murdock in 1970, and to report 14 universals found therein.
\end{abstract}




\section{Introduction}

The discovery of patterned (non-random) phenomena and their subsequent explanation is a familiar method in linguistics and other cross-cultural research. Hurford, for instance, cites a number of examples from the contemporary literature [7, p 59]. The method has even earlier antecedents, since one of the great discoveries in linguistics - the hypothesis of the IndoEuropean language family - was invoked to explain the parallels among Sanskrit and European languages. In the memorable words of Sir William Jones in 1786, Sanskrit bore to Greek and Latin "a stronger affinity, both in the roots of verbs and in the forms of grammar, than could possibly have been produced by accident; so strong indeed that no philologer could examine them all three, without believing them to have sprung from some common source, which, perhaps, no longer exists". Jones applied the same reasoning to the comparative mythology of Greece, Italy, and India [1, p 31--32].

This paper addresses the computerized enumeration of significant cultural and linguistic patterns, specifically implicational universals, as part of a broader research program to build discovery tools for natural and social science [11,12], and specifically linguistics and anthropology $[14,9,13]$.

We proceed in Section 2 to dispute published suggestions that the mechanical generation of universals is inadvisable, by arguing that such claims do not distinguish clearly the discovery of a pattern with its explanation. Section 3 makes use of a principled method that involves permutation tests to estimate whether the enumerated universals are significant. Finally, in Section 5 we mine the rich kinship dataset contributed by G.P. Murdock in a 1970 Ethnology article [8], which to our knowledge has been insufficiently exploited, and list the significant universals contained in these kinship data.

\section{Mechanical Generation of Universals}

In his book Typology and Universals [2, p 50], W. Croft cites the following example which he attributes to J. Greenberg (taken presumably from [5, p 50]). Suppose one observes the following distribution of language types, in which $\mathrm{X}$ means present and -- means absent:

\begin{tabular}{l|cc} 
& Nasal vowels & No nasal vowels \\
\hline Oral vowels & $X$ & $X$ \\
No oral vowels & - & -
\end{tabular}

On pages 50-51, Croft states:

This table may be accounted for by an unrestricted universal that states "All languages have oral vowels." However, there is another possibility. The unattested type with no oral vowels or nasal vowels can be accounted for by the already-existing unrestricted universal "All languages have vowels," and the unattested type with nasal vowels but no oral vowels can be accounted for by the implicational universal "If a language has nasal vowels, then it has oral vowels." Normally, this alternative hypothesis would be rejected on the grounds of simplicity. However, other evidence would suggest that the alternative hypothesis is the correct one. First, there is additional evidence having to do with the markedness of nasal vowels with respect to oral vowels (see chapter 4) that implies that a dependency holds between the two of the sort described by the implicational universal. Second, the unrestricted universal "All languages have vowels" can be explained by the impossibility, or at least extreme difficulty, of articulating speech without vowels, whereas the unrestricted universal "All languages have oral vowels" cannot be accounted for in the same fashion, since a language with only nasal vowels does not have the same articulatory 
restrictions. The lesson to be drawn from this example is that unrestricted and implicational universals cannot be mechanically read off tables of attested and unattested language types. [our italics.] Both wider typological patterns and deeper explanations of what is going on must be appealed to in order to yield the best combination of unrestricted and implicational universals to account for the data. Above all, the choice of the correct generalization(s) to account for the constraints on possible language types is determined by the hypotheses of relationships between parameters.

We agree that an empirically-derived pattern for which, despite significant effort, no causal explanation can be found, assumes the status of at best an unresolved curiosity, or at worst, an accident. Hence, the research is not complete until the observed patterns are explained.

However, the crucial issue here is how to choose between two competing universals, and Croft offers two criteria: (1) formal simplicity, e.g., the pattern $B$ is simpler than the pattern $A \Rightarrow B$, and (2) causal or mechanistic associations, e.g., "if nasal vowels $\Rightarrow$ oral vowels" and "all languages have vowels" possess plausible causal or mechanistic explanations, but "all languages have oral vowels" seemingly do not. In effect, Croft argues for the superiority of causal associations over formal simplicity whenever these two criteria conflict, and we agree with this judgment.

Our main dispute is that the style of argument is misleading, because it blurs the noticing of a pattern with its explanation. This distinction, as noted above, is usually respected in other linguistic contexts; indeed, these are two separate tasks of empirical science ${ }^{1}$. Moreover, noticing typically precedes explanation, and these two tasks can be done by two different people, or as we suggest here, by a computer that generates significant patterns and a linguist or anthropologist who explains them, or instead discards them as accidental curiosities.

We conclude that not only is it possible to mechanically read off universals from tables of attested and unattested language types, but that this is to be recommended in the face of anything other than trivial datasets. The significance test based on permutations should be delegated to a program in any case, trivial or not.

Parenthetically, we do not concede that "mechanical" (computerized) methods are incapable of explanatory reasoning; counterexamples could be adduced from other sciences, e.g., [11]. Our pragmatic aim is to spur research in cross-cultural typology by developing computerized discovery aids.

\section{Estimates of Significance Using Permutation Tests}

Elementary statistical theory warns that whenever one carries out a search for many possible patterns (non-random associations), some patterns will seem significant even if the data are generated randomly. Therefore, some checks should be applied to the collection of universals, whether the universals are generated humanly or by machine.

A good way to get an idea of the chances for seemingly significant patterns is to carry out a permutation test [3] on the data. The logic is this: suppose one has some method for discovering patterns along with some measure of pattern strength. Given a tabular dataset in which the rows correspond to the examples and the columns to the features, randomly permute the values within every column. These permutations will not change the distributions of feature values, which remain as before; only the inter-column relationships will change into random associations. Then, applying the method to the permuted dataset gives one sample of what pattern strengths can be expected by chance. Applying the method to many permuted datasets will give a better sample of the chance patterns. 
We will apply this significance test in what follows, by collecting the strongest "patterns" in many trials of permuted data, and identifying the maximum of these. Then we will reject any pattern from the real data whose strength does not exceed this maximum.

Permutation tests have been used earlier to check the statistical validity of implicational universals, e.g., by D.R. White, although he called them statistical entailments [15]. White developed the idea in the context of dichotomous features, but the technique is equally applicable to categorical data having multiple values, as we will show here with the Murdock data on kinship patterns.

\section{Universals of Kinship Patterns}

The Murdock dataset [8] describes the terminological classification system of eight sets of kin (grandparents, grandchildren, uncles, aunts, nephews and nieces (male speaker), siblings, crosscousins, and siblings-in-law) for 566 societies from 194 of the 200 cultural provinces that Murdock had isolated. This dataset is the most representative compilation of kinship terminologies to date. Moreover, the dataset is based on files of over a thousand complete systems; the published dataset includes only those systems which differ from the remaining systems within the same sampled province. This wealth of kinship information begs to be "mined" for significant patterns.

We have written a straightforward computer program to discover exceptionless universals from data. (Its extension to universals admitting a bounded fraction of exceptions would be a tiny extension.) After verifying that the Murdock data contained no unrestricted universals, we continued with a search for exceptionless implicational universals, i.e., of the form $A \Rightarrow B{ }^{2}$ Since his data have a number of entries that are uncertain (i.e., a value with a question mark), we decided to use the entry and ignore the uncertainty. Of course, when a value was missing entirely (denoted with a dot in his original paper), we left it as missing.

We need to calculate the probability that $\mathrm{K}$ cases will contain no counter-examples of an implication $A \Rightarrow B$, assuming random associations among the feature values. Suppose $b$ is the frequency ratio of $B$ observed in the data. We will define $b^{K}$ to be the needed probability. ${ }^{3}$ Thus, if $A \Rightarrow B$ occurs (without exceptions) 10 times in the data, and the value $B$ is found $20 \%$ of the time, then the probability is $0.2^{10}$. The strength of a pattern could be viewed as the reciprocal of this probability, so that the strongest patterns are those least likely to appear by chance, on the assumption of only random associations.

To determine a significance threshold for simple implications on the Murdock data, we searched for implications on 1000 permuted variations of the data and removed any that did not reach (the rather arbitrary floor of) ten positive examples. Only 39 times were any implications found in the permuted data, i.e., $3.9 \%$ of the time. We want a roughly $99 \%$ assurance that we will not choose as significant an implication that arose by chance, so we pick the tenth smallest of these 39 values, which turns out to be 0.0011 (the absolute smallest was $1.9 \times 10^{-4}$ ). Thus, we will reject any implications in the real data whose probability is greater than 0.0011 .

The program's exhaustive search of the real data turned up just one implication having at least ten positive examples:

If the aunts pattern is Relative Age, then the grandchildren pattern is Merging. ( $P a S i=K \Rightarrow$ $\mathrm{GrCh}=A$ )

The implication's consequent (Merging grandchildren) occurs over half the time, but the 15 positive examples of this implication means that its probability (as defined above) is $5.4 \times 10^{-5}$ (which is even smaller than the smallest value seen among the 1000 permutations). The Appendix contains an expanded description of the terms in this and all other universals below. 
The 15 societies are not obviously highly related, as can be judged either by the Provinces originally assigned by Murdock: Daka (Adamawa), Rega (South Equatorial Bantu), Burmese (South Burma), Lepcha (Tibet), Lao, Siamese (Thai), Cambodians (Cambodia), Mnong Gar, Jarai (Montagnards), Semang (Semang-Sakai), Iban (Borneo), Mangarevans (Eastern Polynesia), Selung (Sea Gypsies), Miyakans (Japan and Ryukyus), and Wichita (Caddoans), or by their linguistic familes (source: Ethnologue Language Family Index at www.sil.org/ethnologue): Daka, Rega (Niger-Congo), Burmese, Lepcha (Sino-Tibetan), Lao, Siamese (Daic), Cambodians, Mnong Gar, Semang (Austro-Asiatic), Iban, Jarai, Mangarevans, Selung (Austronesian), Miyakans (Japanese), Wichita (Caddoan). Thus we accept this universal implication as genuinely significant and calling for explanation.

We then searched for universals of the next simplest form $A \wedge B \Rightarrow C$, which one might call doubly contingent universals, in line with the general sequence that $C$ is an unrestricted universal and $B \Rightarrow C$ is a universal that is singly contingent on the truth of $B$. (Such universals are often referred to as "complex implicational universals" in the literature.) Many such universals turned up, so again we performed 1000 trials of permutation tests to estimate a significance threshold. In this case, the smallest probability seen for "universals" supported by at least ten cases was $6.7 \times$ $10^{-6}$; the eleventh smallest of $2.3 \times 10^{-4}$ provides our desired $99 \%$ threshold. Thus, we accept only universals whose probability falls below this value.

There were 14 doubly-contingent universals that passed our permutation test of significance and which met or exceeded our arbitrary minimum of 10 examples (the notation follows Murdock):

1. $P a S i=E \wedge C r C o=B \Rightarrow P a B r=C$. $\left(\right.$ examples $\left.=25, \operatorname{prob}=6.0 \times 10^{-21}\right){ }^{4}$

If the aunts pattern is Skewed Bifurcate Collateral and the cross-cousins pattern is Iroquois, then the uncles pattern is Skewed Bifurcate Collateral.

2. $P a B r=E \wedge S b C h=F \Rightarrow P a S i=D$. (examples $=19$, prob $\left.=3.2 \times 10^{-18}\right)$.

If the uncles pattern is Generation and the nephews and nieces (male speaking) pattern is SexDifferentiated Lineal, then the aunts pattern is Generation.

3. $P a B r=E \wedge \mathrm{GrPa}=A \Rightarrow P a S i=D$. (examples=13, prob=8.7 $\left.\times 10^{-13}\right)$.

If the uncles pattern is Generation and the grandparents pattern is Bisexual, then the aunts pattern is Generation.

4. $P a B r=D \wedge S b-i l=B \Rightarrow P a S i=C$. (examples $=14$, prob $=7.3 \times 10^{-12}$ ). If the uncles pattern is Lineal and the siblings-in-law pattern is Simple Bisexual, then the aunts pattern is Lineal.

5. $P a B r=E \wedge G r C h=A \Rightarrow P a S i=D$. (examples=12, prob $\left.=7.8 \times 10^{-12}\right)$.

If the uncles pattern is Generation and the grandchildren pattern is Merging, then the aunts pattern is Generation.

6. $P a S i=A \wedge S b-i l=D \Rightarrow P a B r=B$. (examples $=18$, prob $\left.=4.3 \times 10^{-11}\right)$.

If the aunts pattern is Simple Bifurcate Collateral and the siblings-in-law pattern is Opposite Sex, then the uncles pattern is Simple Bifurcate Collateral.

7. $P a S i=A \wedge S b-i l=B \Rightarrow P a B r=B$. (examples $=16$, prob $\left.=6.1 \times 10^{-10}\right)$.

If the aunts pattern is Simple Bifurcate Collateral and the siblings-in-law pattern is Simple Bisexual, then the uncles pattern is Simple Bifurcate Collateral.

8. $P a S i=C \wedge S i b l=C \Rightarrow P a B r=D$. (examples $=11$, prob $=6.2 \times 10^{-10}$ ).

If the aunts pattern is Lineal and the siblings pattern is Yoruban, then the uncles pattern is Lineal.

9. $P a S i=E \wedge G r P a=B \Rightarrow P a B r=C$. (examples $=10$, prob $\left.=8.3 \times 10^{-9}\right)$. 
If the aunts pattern is Skewed Bifurcate Collateral and the grandparents pattern is Merging, then the uncles pattern is Skewed Bifurcate Collateral.

10. $P a S i=E \wedge S b-i l=K \Rightarrow P a B r=C$. (examples $=10$, prob $\left.=1.7 \times 10^{-8}\right)$.

If the aunts pattern is Skewed Bifurcate Collateral and the siblings-in-law pattern is Strongly Differentiated, then the uncles pattern is Skewed Bifurcate Collateral.

11. $P a S i=B \wedge S i b l=E \Rightarrow P a B r=A$. (examples $=12$, prob $\left.=4.2 \times 10^{-7}\right)$.

If the aunts pattern is Bifurcate Merging and the siblings pattern is Kordofanian, then the uncles pattern is Simple Bifurcate Merging.

12. $P a S i=B \wedge$ Sibl $=D \Rightarrow P a B r=A$. (examples $=11$, prob $=1.4 \times 10^{-6}$ ).

If the aunts pattern is Bifurcate Merging and the siblings pattern is Algonkian, then the uncles pattern is Simple Bifurcate Merging.

13. $P a S i=B \wedge S b-i l=E \Rightarrow P a B r=A$. (examples $=10$, prob $\left.=6.3 \times 10^{-6}\right)$.

If the aunts pattern is Bifurcate Merging and the siblings-in-law pattern is Null, then the uncles pattern is Simple Bifurcate Merging.

14. $\mathrm{GrCh}=B \wedge \mathrm{PaSi}=C \Rightarrow \mathrm{GrPa}=A$. (examples=16, $\left.\mathrm{prob}=1.3 \times 10^{-4}\right)$.

If the grandchildren pattern is Bisexual and the aunts pattern is Lineal, then the grandparents pattern is Bisexual.

We make the following observations. First, some sets of universals, viz. [\#1, \#9, \#10], [\#2, \#3, $\# 5$ ], [\#6, \#7], and [\#11, \#12, \#13], may be collapsed into more compact formulae, using disjunction. E.g. [\#6, \#7] can be expressed as:

$P a S i=A \wedge S b-i l=[D \vee B] \Rightarrow P a B r=B$.

If the aunts pattern is Simple Bifurcate Collateral and the siblings-in-law pattern is Opposite Sex or Simple Bisexual, then the uncles pattern is Simple Bifurcate Collateral.

Secondly, 14 universals involve an implication between the relatives uncle-aunt (or vice versa), and one universal (the last one) between grandchild and grandparent; all of these pairs of relatives are "symmetrical" with respect to ego in a genealogical grid: uncle and aunt along the dimension of collaterality, grandchild and grandparent along the dimension of lineality.

And, thirdly, all universals express a uniformity between the patterns for the pairs uncles-aunts and grandchild-grandparent (Murdock states that the aunt and uncle patterns in universals \#11, $\# 12$, and \#13 are analogous, even though the names differ; cf. also the Appendix). However, these uniformities are not absolute, otherwise they would have shown up as singly-contingent universals; rather, each is mediated by another pattern.

For example, in the first universal, the relation between aunt and uncle is contingent on a value of Iroquois for the cross-cousins pattern. Looking more closely at why the simpler implication did not show up as an exceptionless universal, the data reveal that the aunt pattern occurs 63 times, but in only 56 of these does the uncle pattern hold (the seven exceptions are the Luguru, Akha, Eastern Pomo, Miwok, Southern Ute, Hano, and Tepehuan societies). Depending on taste, one might prefer a simpler universal having an $11 \%$ exception rate to our more complex universals. Similarly, the data reveal that the simplified universals \#6 and \#7 (removing the contingencies on siblings-in-law) have an exception rate of $19 \%$. On the other hand, the simplified universals \#2, \#3, and \#5 would have an exception rate of only 0.04 (one - the Samoans - out of 28), so it is probably best to favor the singly-contingent, 1-exception universal in this case. The exception rates for all 14 simplified (i.e., keeping only the relation between aunt and uncle or grandparents and grandchildren) universals are \#1 (7/63), \#2 (1/28), \#3 (1/28), \#4 (8/81), \#5 (1/28), \#6 
(29/152), \#7 (29/152), \#8 (15/88), \#9 (7/63), \#10 (7/63), \#11 (22/144), \#12 (22/144), \#13 (22/144), and \#14 (15/89).

We welcome contributions or suggestions of datasets for similar analysis. A computer file of the Murdock data can be obtained by email request to valdes@cs.cmu.edu.

Acknowledgments. This work was supported in part by the grant IRI-9421656 from the (USA) National Science Foundation and by the NSF Division of International Programs. We thank Michael Strauss for copying the Murdock data onto the computer. 


\section{References}

1. G. Cannon. Jones's "Sprung from some common source". In S.M. Lamb and E.D. Mitchell, editors, Sprung from some common source: Investigations into the prehistory of languages, pages 23-47, Stanford University Press, Stanford, 1991.

2. W. Croft. Typology and universals. Cambridge University Press, 1990.

3. P. Good. Permutation tests. Springer Verlag, New York, 1994.

4. J. H. Greenberg. Language universals (with special reference to feature hierarchies). Mouton \& Co, The Hague, 1966.

5. J. H. Greenberg. Typologies and cross-linguistic generalizations. In J. H. Greenberg, editor, Universals of human language, vol.1, pages 33--59. Stanford University Press, Stanford, 1978.

6. J. H. Greenberg. Universals of kinship terminology: their nature and the problem of their explanation. In J. Maquet, editor, On linguistic anthropology: Essays in honor of Harry Hoijer, pages 9--32. Udena Publications, Malibu, 1980.

7. J. Hurford. The significance of linguistic generalizations. Language 53(3):574--620, 1977.

8. G.P. Murdock. Kin term patterns and their distribution. Ethnology 9:165--207.

9. V. Pericliev and R. E. Valdés-Pérez . Automatic componential analysis of kinship semantics with a proposed structural solution to the problem of multiple models. Anthropological Linguistics 40:272-317, 1998.

10. H. A. Simon. On judging the plausibility of theories. In Models of discovery, pages 25--45. Reidel, Boston, 1977.

11. R. E. Valdés-Pérez. Some recent human/computer discoveries in science and what accounts for them. Al Magazine, 16(3):37--44, Fall 1995.

12. R. E. Valdés-Pérez . Computer science research on scientific discovery. Knowledge Engineering Review, 11(1):57--66, 1996.

13. R. E. Valdés-Pérez and V. Pericliev. Concise, Intelligible, and Approximate Profiling of Numerous Classes. Machine Learning. Submitted for publication.

14. R. E. Valdés-Pérez and V.Pericliev. Maximally parsimonious discrimination: A generic task from linguistic discovery. In Proceedings of 14th National Conference on Artificial Intelligence, pages 515--520, Menlo Park, CA, 1997. AAAI Press.

15. D.White. Statistical entailments and the galois lattice. Social Networks, 18:201--215, 1996. 


\section{Footnotes}

${ }^{1}$ The typical stages in the methodology of empirical, pattern-seeking science are well described in [10].

${ }^{2}$ The fact that we found no unrestricted universals should not be taken to contradict [4] and [6], which claim that all kinship systems use at least the features generation, blood relationship, and sex. Greenberg found these unrestricted universals in data formulated in terms of Kroeber's categories, but the Murdock data is stated in different terms; for an idea of the kin patterns Murdock uses, see the Appendix. It may be possible to re-express the Murdock data in terms of Kroeber's features and then apply our same machinery, but this is beyond the scope of this paper.

${ }^{3} A n$ alternative would be to assume a fixed supply of $B$ values and calculate the probability to be $B(B-1) \ldots(B-K+1) / N(N-1) \ldots(N-K+1)$ where $b=B / N$.

${ }^{4}$ The 25 societies are: Baiga, Buduma, Chenchu, Cocopa, Diegueno, Garo, Ila, Kerala, Keweyipaya, Kgatla Tswana, Khasi, Kiliwa, Luiseno, Magpie Miao, Mbau Fijians, Mossi, Nlaria Gond, Reddi, Serrano, Sinhalese, Songhai, Telugu, Vedda, Venda, and Yuma. 
Appendix - Relevant Descriptions from Murdock

\begin{tabular}{|c|c|}
\hline \multicolumn{2}{|l|}{ Grandparents } \\
\hline Bisexual & $\begin{array}{l}\text { Two terms, distinguished by sex, which can be } \\
\text { glossed as "grandfather" and "grandmother". }\end{array}$ \\
\hline Merging & $\begin{array}{l}\text { A single undifferentiated term, which can be glossed } \\
\text { as "grandparent." }\end{array}$ \\
\hline \multicolumn{2}{|r|}{ as grarrupartir. } \\
\hline Bisexual & $\begin{array}{l}\text { Two terms, distinguished by sex, which can be } \\
\text { glossed as "grandson" and "granddaughter." }\end{array}$ \\
\hline Merging & $\begin{array}{l}\text { A single undifferentiated term, which can be glossed } \\
\text { as "grandchild." }\end{array}$ \\
\hline \multicolumn{2}{|l|}{ Uncles } \\
\hline Simple Bifurcate Collateral & $\begin{array}{l}\text { Two special terms, distinguished by the sex of the } \\
\text { connecting relative, which can be glossed as } \\
\text { "paternal uncle" and "maternal uncle". }\end{array}$ \\
\hline Skewed Bifurcate Collateral & $\begin{array}{l}\text { Three special terms, distinguished by the sex of the } \\
\text { connecting relative and in the case of paternal } \\
\text { uncles also by relative age, which can be glossed as } \\
\text { "father's elder brother," "father's younger brother," } \\
\text { and "mother's brother." }\end{array}$ \\
\hline Simple Bifurcate Merging & $\begin{array}{l}\text { A single special term which can be glossed as } \\
\text { "mother's brother," paternal uncles being } \\
\text { terminologically equated with father. Analogous to } \\
\text { Pattern Bifurcate Merging for aunts }\end{array}$ \\
\hline Lineal & $\begin{array}{l}\text { A single special term, which can be glossed as } \\
\text { "uncle," applying to both the father's and the } \\
\text { mother's brothers and distinguishing them from } \\
\text { father. }\end{array}$ \\
\hline Generation & $\begin{array}{l}\text { Special terms are lacking for both paternal and } \\
\text { maternal uncles, who are terminologically equated } \\
\text { with father. }\end{array}$ \\
\hline \multicolumn{2}{|l|}{ Aunts } \\
\hline Relative Age & $\begin{array}{l}\text { Two special terms, distinguished by age relative to } \\
\text { the connecting relative, which can be glossed as } \\
\text { "parent's elder sister" and "parent's younger sister." }\end{array}$ \\
\hline Simple Bifurcate Collateral & $\begin{array}{l}\text { Two special terms, distinguished by the sex of the } \\
\text { connecting relative, which can be glossed as } \\
\text { "paternal aunt" and "maternal aunt." }\end{array}$ \\
\hline Lineal & $\begin{array}{l}\text { A single special term, which can be glossed as } \\
\text { "aunt," applying to both the father's and the mother's } \\
\text { sisters and distinguishing them from mother. }\end{array}$ \\
\hline Generation & $\begin{array}{l}\text { Special terms are lacking for both maternal and } \\
\text { paternal aunts, who are terminologically equated } \\
\text { with mother. }\end{array}$ \\
\hline Skewed Bifurcate Collateral & $\begin{array}{l}\text { Three special terms, distinguished by the sex of the } \\
\text { connecting relative and in the case of maternal aunts } \\
\text { also by relative age, which can be glossed as } \\
\text { "father's sister," "mother's elder sister," and } \\
\text { "mother's younger sister." }\end{array}$ \\
\hline Bifurcate Merging & $\begin{array}{l}\text { A single special term which can be glossed as } \\
\text { "father's sister," maternal aunts being } \\
\text { terminologically equated with mother. Analogous to } \\
\text { Pattern Simple Bifurcate Merging for uncles. }\end{array}$ \\
\hline
\end{tabular}




\begin{tabular}{|l|l|}
\hline Nephews \& Nieces (male speaking) & Two special terms, differentiated by sex, which can \\
\hline Sex-Differentiated Lineal & ge glossed as "nephew" and "niece". \\
\hline Siblings & $\begin{array}{l}\text { Three terms, distinguished by relative age and for } \\
\text { elder siblings also by sex, which can be glossed as } \\
\text { "elder brother," "elder sister," and "younger sibling." }\end{array}$ \\
\hline Algonkian & $\begin{array}{l}\text { A single undifferentiated term, which can be glossed } \\
\text { as "sibling." }\end{array}$ \\
\hline Kordofanian & $\begin{array}{l}\text { Two terms, distinguished by relative age, which can } \\
\text { be glossed as "elder sibling" and "younger sibling." }\end{array}$ \\
\hline Yoruban & $\begin{array}{l}\text { One or more special terms for first cross-cousins, } \\
\text { which differ from those for siblings, parallel cousins, } \\
\text { and avuncular and nepotic relatives. }\end{array}$ \\
\hline Cross-Cousins & $\begin{array}{l}\text { Two terms, differentiated by sex, which can be } \\
\text { glossed as "brother-in-law" and "sister-in-law". }\end{array}$ \\
\hline Iroquois & $\begin{array}{l}\text { Three terms, distinguished by relative sex and for } \\
\text { siblings-in-law of the speaker's sex also by sex, } \\
\text { which can be glossed as "sibling-in-law of opposite } \\
\text { sex," "brother-in-law (ms)," and "sister-in-law (ws)." }\end{array}$ \\
\hline Siblings-In-Law & $\begin{array}{l}\text { Special affinal terms are absent or rare, siblings-in- } \\
\text { law being called by terms for consanguineal } \\
\text { relatives, mainly those applying primarily to cousins } \\
\text { rather than siblings. }\end{array}$ \\
\hline Simple Bisexual & $\begin{array}{l}\text { Any pattern having more than eight distinct terms for } \\
\text { siblings-in-law and thus necessarily involving a } \\
\text { proliferation of terms based on distinctions of relative } \\
\text { age. }\end{array}$ \\
\hline Null & \multicolumn{1}{|c|}{ apposite Sex } \\
\hline Strongly Differentiated
\end{tabular}

